\title{
Soil microbial respiration in arctic soil does not acclimate to 2 temperature
}

\section{Authors:}

Iain P. Hartley ${ }^{1, *}$, David W. Hopkins ${ }^{1,2}$, Mark H. Garnett ${ }^{3}$, Martin Sommerkorn ${ }^{4}$ and Philip A. Wookey ${ }^{1}$

\section{Affiliations:}

${ }^{1}$ School of Biological and Environmental Sciences, University of Stirling, Stirling, FK9 4LA, UK

${ }^{2}$ Scottish Crop Research Institute, Invergowrie, Dundee, DD2 5DA, UK

${ }^{3}$ NERC Radiocarbon Laboratory, Scottish Enterprise Technology Park, Rankine Avenue, East Kilbride, Glasgow G75 0QF

${ }^{4}$ Macaulay Institute, Craigiebuckler, Aberdeen, AB15 8QH, UK

\section{E-mails:}

Iain P. Hartley: $\quad$ i.p.hartley@stir.ac.uk

David W. Hopkins: d.w.hopkins@scri.ac.uk

Mark H. Garnett: $\quad$ M.Garnett@nercrcl.gla.ac.uk

Martin Sommerkorn: M.Sommerkorn@macaulay.ac.uk

Philip A. Wookey: philip.wookey@stir.ac.uk

Running title: Thermal acclimation of microbial respiration

Keywords: Acclimation, adaptation, arctic, carbon cycling, climate change, $\mathrm{CO}_{2}$, respiration, microbial community, soil, temperature

Article type: Letter

Number of words in abstract: 169

Number of words in article: 4497

Number of references: 50

Number of figures: 2

Number of tables: 0

\section{Correspondence author $(*)$ :}

Iain P. Hartley, School of Biological and Environmental Sciences, University of Stirling, Stirling, FK9 4LA, UK; E-mail: i.p.hartley@stir.ac.uk

Tel: +44 1786 467757; Fax: +44 1786467843 


\section{Abstract}

2

4 arctic soils could accelerate climate change. However, declines in the response of soil

5 respiration to warming in long-term experiments suggest that microbial activity

6 acclimates to temperature, greatly reducing the potential for enhanced $\mathrm{C}$ losses. As

7 reduced respiration rates could be equally caused by substrate depletion, evidence for

8 thermal acclimation remains controversial. To overcome this problem, we carried out

9 a cooling experiment with soils from arctic Sweden. If acclimation causes the 10 reduction in respiration observed in warming experiments, then it must also

11 subsequently increase rates post cooling. We demonstrate that thermal acclimation did 12 not occur. Rather, over the following 90 days, cooling resulted in a further reduction 13 in respiration which was only reversed by extended re-exposure to warmer 14 temperatures. We conclude that, over the time scale of a few weeks to months, 15 warming-induced changes in the microbial community in arctic soils will amplify the 16 instantaneous increase in the rates of $\mathrm{CO}_{2}$ production.

20 Key words: Adaptation, acclimation, arctic, carbon cycling, climate change, $\mathrm{CO}_{2}$, 21 respiration, microbial community, soil, temperature 


\section{INTRODUCTION}

3 Rising global temperatures are likely to increase the rate of soil organic matter

4 decomposition resulting in a substantial release of $\mathrm{CO}_{2}$ (Raich \& Schlesinger 1992;

5 Kirschbaum 1995), and this phenomenon has the potential to accelerate climate

6 change by up to $40 \%$ (Cox et al. 2000). In fact, the importance of soil C-cycling is

7 recognized in the updated IPCC scenarios (IPCC 2007). However, increasingly,

8 ecologists are recognizing that in order to predict long-term trends in ecosystem $\mathrm{C}$

9 fluxes and biological feedbacks, greater emphasis needs to be placed on measuring

10 potential acclimation and adaptation responses (Oechel et al. 2000; Enquist 2007).

11 Critically, acclimation has the potential to reduce the projected soil-C losses 12 associated with global warming (Luo et al. 2001).

13 Respiratory thermal acclimation has been defined as "the subsequent 14 adjustment in the rate of respiration to compensate for an initial change in 15 temperature" (Atkin \& Tjoelker 2003). When many plant species are exposed to 16 higher temperatures for a prolonged period of time, physiological acclimation results 17 in a reduction in respiration rates allowing for the maintenance of a positive $\mathrm{C}$ balance 18 (Atkin \& Tjoelker 2003). Similarly, thermal acclimation of respiration has been 19 demonstrated for both ectomycorrhizal (Malcolm et al. 2008) and arbuscular 20 mycorrhizal fungi in soils (Heinemeyer et al. 2006), and the fungal symbiont in 21 lichens (Lange \& Green 2005). Further, although cooling reduces respiration rates, 22 prolonged exposure often results in a subsequent increase in plant respiration rates, 23 allowing for the maintenance of critical metabolic processes (Armstrong et al. 2006). 24 Many physiological modifications have been observed in microbial communities 25 present at low temperatures which allow for continued growth (D'Amico et al. 2006), 
1 and this may suggest that there is potential for up-regulation of activity following extended exposure to the cold.

In soils, although increased rates of respiration have been observed in many warming experiments (Rustad et al. 2001), the magnitude of the initial positive response to temperature often declines over time (Rustad et al. 2001; Eliasson et al. 2005). Because alterations in microbial community structure accompany soil warming in both the field (Zhang et al. 2005) and the laboratory (Zogg et al. 1997; Andrews et al. 2000; Pettersson \& Bååth 2003; Pietikäinen et al. 2005), as well as in response to seasonal changes in temperature (Schadt et al. 2003; Lipson \& Schmidt 2004; Wallenstein et al. 2007), the reduction in the initial positive response of soil respiration to warming may be the result of acclimation ${ }^{1}$ of microbial respiration (Luo et al. 2001; Balser et al. 2006; Luo 2007; Wan et al. 2007).

Investigating temperature responses of soil respiration and microbial activity is complicated by the fact that the effect of experimental soil warming is confounded by the depletion of the most readily-decomposable soil $\mathrm{C}$ fractions. This could equally explain the reduction in respiration rates observed in long-term studies (Rustad et al. 2001; Eliasson et al. 2005). Consequently, the main evidence for thermal acclimation of soil microbial respiration remains questionable (Kirschbaum 2004; Eliasson et al. 2005; Knorr et al. 2005; Hartley et al., 2007b).

Identifying the potential for thermal acclimation of microbial respiration in arctic regions is particularly important due to the high rates of global warming already being experienced at high latitudes (ACIA 2005), the general sensitivity of communities close to environmental extremes to changing conditions, and the large amounts of $\mathrm{C}$ stored in these systems (Post et al. 1982). In addition, substantial

\footnotetext{
${ }^{1}$ As the long-term response of microbial respiration to changes in temperature almost certainly involves a genetic component, acclimation is probably an inappropriate term for this response. We will return the issue of terminology in the discussion section.
} 
1 changes in microbial communities have been observed between seasons in tundra

2 soils (Schadt et al. 2003; Lipson \& Schmidt 2004; Wallenstein et al. 2007) raising the

3 possibility of acclimation of microbial respiration in these systems. Accurate

4 predictions of the long-term rates of $\mathrm{C}$ and nitrogen cycling in arctic soils, which in

5 turn may determine total ecosystem C storage (Hobbie et al. 2000), plant productivity

6 (van Wijk et al. 2005) and species composition (Weintraub \& Schimel 2005), require

7 a much greater understanding of microbial acclimation responses.

Here we present the results from one of the first studies to investigate the

9 effect of an extended period of cooling on microbial respiration, utilizing organic soils

10 taken from a sub-arctic tundra heath system in northern Sweden. If thermal

11 acclimation is responsible for the down-regulation of microbial activity observed at

12 high temperatures, then microbial activity must be gradually up-regulated when

13 temperatures are reduced. This is because, as a compensatory response, acclimation

14 must be reversible; otherwise temporary exposure to higher temperatures would result

15 in a permanent down-regulation of respiration, preventing the recovery of rates even

16 when temperature have declined, for example between summer and winter. In support

17 of this logic, changes in soil microbial community structure have been observed both

18 when soil temperatures increase (Andrews et al. 2000; Lipson \& Schmidt 2004) and

19 decrease (Schadt et al. 2003; Monson et al. 2006), and the thermal optimum for the

20 activity of key C-cycling enzymes has been to shown increase and decrease with

21 seasonal changes in temperature (Fenner et al. 2005). Furthermore, thermal

22 acclimation of plant respiration, in response to seasonal and experimental changes in

23 temperature, is dynamic and reversible, occurring both in response to warming and

24 cooling (Atkin \& Tjoelker 2003; Atkin et al. 2005; Zaragoza-Castells et al. 2008). 
Therefore, the use of experimental cooling allowed us to minimize the

2 confounding factor of warming-induced substrate depletion (substrate depletion will

3 occur at a slightly faster rate in the control soils, but total carbon losses should be

4 sufficiently small to avoid confounding the results) whilst still determining whether

5 soil microbial respiration acclimates to temperature. We demonstrate that (i) soil

6 microbial respiration does $\underline{\text { not }}$ acclimate to temperature, (ii) the short-term

7 temperature sensitivity of respiration is unaltered by the prevailing temperature

8 regime, and (iii) when soil temperatures were reduced for an extended period of time,

9 changes in the microbial community resulted in a further decrease in the baseline rate

10 of respiration, lowering rates of $\mathrm{CO}_{2}$ production beyond the instantaneous response to

11 temperature.

13 METHODS

\section{Soil sampling and incubation}

17 On $13^{\text {th }}$ September 2006 , twenty-six soil cores (68 mm diameter and $100 \mathrm{~mm}$ deep)

18 were removed from an area of tundra heath above the tree-line (at an altitude of

19 approximately $750 \mathrm{~m}$ ), about $200 \mathrm{~km}$ north of the Arctic Circle, near Abisko, northern

20 Sweden $\left(68^{\circ} 18^{\prime} 07^{\prime}, \mathrm{N}, 18^{\circ} 51^{\prime} 16^{\prime \prime} \mathrm{E}\right)$. The mean annual temperature at this site is $-1^{\circ} \mathrm{C}$

21 with mean January and July temperatures of -12 and $11^{\circ} \mathrm{C}$, respectively (van Wijk et

22 al. 2005). The dominant plant species are ericaceous shrubs, mainly of the genera

23 Vaccinum and Empetrum, with some dwarf birch (Betula nana L.) also present. The

24 soils have an organic horizon of between approximately 5 and $20 \mathrm{~cm}$ deep (mean

25 depth $=11 \mathrm{~cm}$ ), overlying well-drained medium to coarse-grained till deposits with 
1 some large boulders and intermittent pockets of mineral soil. In this study, only the

2 organic horizon was sampled. This soil is well-suited for investigating the long-term

3 response of soil microbial respiration to changing temperatures because it contains a

4 large amount of $\mathrm{C}$, but does not experience waterlogging (except briefly during spring

5 melt), and field conditions can thus be well replicated in the laboratory. Further,

6 issues such as the mineral protection of SOM changing with temperature are avoided

7 (Rasmussen et al. 2006).

The soils were transported to the University of Stirling using cooled air cargo.

9 The water content of the soil was raised to water holding capacity (WHC) and 10 samples were placed in an incubator (MIR-153, SANYO, Loughborough, UK) at $1110^{\circ} \mathrm{C}\left( \pm 1^{\circ} \mathrm{C}\right)$ for 110 days to allow respiration rates to stabilize as the most labile $\mathrm{C}$ 12 pool was depleted and for the microbial community to adjust to this temperature. 13 Sixteen cores were then transferred to a separate incubator (same make and model) set 14 at $2^{\circ} \mathrm{C}\left( \pm 1^{\circ} \mathrm{C}\right)$. Of these 16 cores, 10 were then maintained at $2^{\circ} \mathrm{C}$ for 90 days (high15 low treatment), and the other 6 cores were returned to the $10^{\circ} \mathrm{C}$ incubator after 60 days 16 at $2^{\circ} \mathrm{C}$ (the high-low-high treatment). The remaining 10 cores were maintained at $10^{\circ} \mathrm{C}$ 17 for the whole 200-day incubation (constant high treatment). Soil samples were 18 maintained at WHC throughout by frequent addition of distilled water. Data loggers 19 (Tinytag® Plus, Gemini Data Loggers Ltd., Chichester, UK) connected to thermistor 20 probes (PB-5001, Gemini Data Loggers Ltd., Chichester, UK) confirmed that the 21 temperatures in the incubators remained stable. The incubation temperatures used are 22 within the range regularly experienced by the soil during the growing season, and soil 23 temperatures were not reduced below $0^{\circ} \mathrm{C}$ to avoid changes in substrate availability 24 caused by the alterations in the proportion of liquid water present (Mikan et al. 2002; 25 Monson et al. 2006) and freeze-thaw effects. 


\section{Respiration measurements}

3 Respiration measurements were carried out using an infra-red gas analyzer (EGM-4,

4 PP Systems, Hitchen, UK) connected to an incubation chamber (700 ml Lock \&

5 Lock ${ }^{\circledR}$ container, Hana Cobi Plastic Co Ltd., Seoul, Korea) in a closed loop

6 configuration. The rate of $\mathrm{CO}_{2}$ accumulation in the headspace was logged every 1.6

7 seconds until a $35 \mathrm{ppm}$ increase in $\mathrm{CO}_{2}$ concentration had occurred. Therefore,

8 measurements were made close to ambient $\mathrm{CO}_{2}$ concentrations. Respiration rates were

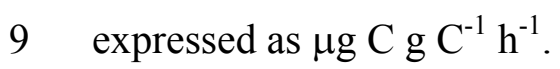

10 Finally, at the end of the incubation, the short-term temperature sensitivity of

11 respiration (between 2 and $10^{\circ} \mathrm{C}$ ) in six replicates taken from the high-low and

12 constant high treatments was measured. The samples were transferred to an incubator

13 at $2^{\circ} \mathrm{C}$, and one day later respiration rates were measured. The incubator temperature

14 was then raised to $6^{\circ} \mathrm{C}$ and subsequently $10^{\circ} \mathrm{C}$, before being reduced back to $6^{\circ} \mathrm{C}$ and

15 then $2^{\circ} \mathrm{C}$. The soils were maintained at each new temperature for approximately 24

16 hours. Mean respiration rates were calculated at each temperature to allow changes in

17 baseline rates of respiration over the five-day experiment to be included in the $\mathrm{Q}_{10}$

18 calculation (Fang et al. 2005). Changes in baseline rates of respiration could have

19 been caused by changes in soil moisture (although samples were watered each day),

20 or growth of microbial biomass in the previously cooled soils (Monson et al. 2006).

21 The aim of this temperature manipulation was to determine whether the direct or

22 instantaneous response of respiration to temperature had been altered by the cooling

23 treatment and, therefore, we wanted to account for any changes in baseline rates.

24 Respiration rates were natural log transformed and plotted against temperature. Linear 
1 regressions were then used to calculate the slope $(\mathrm{K})$ of the relationship and $\mathrm{Q}_{10}$

2 values calculated using Equation 1.

3

$4 \quad \mathrm{Q}_{10}=\mathrm{e}^{10 \mathrm{~K}}$

Equation 1

6 Substrate-induced respiration

8 At the end of the experiment, soil from all 26 samples was sieved through a $2 \mathrm{~mm}$

9 mesh, large root fragments were removed and sub-samples dried for moisture and C

10 content (loss on ignition) determination. After all samples had been incubated at $10^{\circ} \mathrm{C}$

11 over-night, a solution containing $15 \mathrm{mg}$ of glucose per gram of soil $\mathrm{C}$ was added to a

$125 \mathrm{~g}$ (fresh wt.) sub-sample of each soil, with the corresponding volume $\left(1 \mathrm{~cm}^{3}\right)$ of

13 distilled water added to a further $5 \mathrm{~g}$ sub-sample. Total $\mathrm{CO}_{2}$ production after 24 hours

14 at $10^{\circ} \mathrm{C}$ was measured using gas chromatography (Model 90-P, Varian Aerograph,

15 Palo Alto, CA, USA). The difference between the two treatments was considered to 16 represent substrate-induced respiration (SIR), which is considered to be proportional 17 to the size of microbial biomass (Anderson \& Domsch 1978).

\section{Statistics}

21 Statistical analyses were carried out using SPSS (SPSS Science, version 15,

22 Birmingham, UK). Before cooling, one-way ANOVAs were used to determine

23 whether there were any significant differences between the respiration rates of the

24 soils in the different temperature treatment groups. Post-cooling, for the high-low and 25 high-low-high samples, linear regressions were used to determine whether the 
1 respiration rates changed significantly over the following 60 days. After the high-low-

2 high samples were returned to $10^{\circ} \mathrm{C}$, repeated measures ANOVAs and paired $t$-tests

3 were used to determine whether there were significant differences between dates, both

4 immediately before and after the cooling treatment was applied, and between the

5 high-low-high and constant high treatments. At the end of the incubation, independent

6 samples $t$-tests were used to determine whether the short-term temperature sensitivity

7 of respiration differed significantly between the high-low and constant high soils, and

8 paired $t$-tests were used to determine whether respiration rates differed between the

9 increasing and decreasing phase of the manipulation. An independent samples $t$-test

10 was used to determine whether the rate of SIR differed between samples that were at

$11 \quad 10^{\circ} \mathrm{C}$ at the end of the experiment (as there was no significant difference between the 12 two treatments, constant high and high-low-high soils were grouped together) 13 compared with the soils that were at $2^{\circ} \mathrm{C}$ at the end of the incubation (the high-low 14 soils).

\section{RESULTS}

\section{Respiration rates}

20 Before cooling, there were no significant differences in respiration rates measured at

$2110^{\circ} \mathrm{C}$ between the soils in the three temperature treatments $(\mathrm{P}=0.622$; Fig. 1a). On

22 day 110, the high-low and high-low-high cores were cooled from $10^{\circ} \mathrm{C}$ to $2^{\circ} \mathrm{C}$ and the

23 following day the respiration rates had declined by about $67 \%$. Over the following 60

24 days, rather than an increase in the rate of respiration indicative of acclimation, 25 respiration rates declined significantly by on average $28 \%$ (Fig. 1b). The effect of 
1 temperature manipulation on the rate of respiration can be expressed using $\mathrm{Q}_{10}$

2 functions (Equation 1):

$3 \quad \mathrm{R}_{\mathrm{T}}=\mathrm{R}_{0} * \mathrm{Q}_{10}{ }^{(\mathrm{T} / 10)}$

Equation 1

5 Where $\mathrm{R}_{\mathrm{T}}$ is the respiration rate at temperature $(\mathrm{T}), \mathrm{R}_{0}$ is the respiration rate at $0^{\circ} \mathrm{C}$ 6 and $\mathrm{Q}_{10}$ is the proportion change in the rate of respiration given a $10^{\circ} \mathrm{C}$ change in 7 temperature. The equations corresponding to the mean effect of cooling for 1 and 60

8 days across both the high-low and high-low-high soils are as follows:

9

12 The reduction in the baseline rate of respiration caused by the cooling treatment has

13 increased the apparent temperature sensitivity of respiration by $\sim 50 \%$ (i.e. $Q_{10}$ values 14 have increased from 4.01 to 6.06$)$. respiration rates only occurred when soil temperatures were reduced. These results

21 demonstrate that sustained exposure to low temperatures amplified the negative effect 22 of cooling on soil respiration rates.
Day 1

Day 60 rates stabilized with there being no significant subsequent change in rates between days 157 and 200 (linear regression: $\mathrm{P}=0.404$; Fig. 1). In contrast, over the entire incubation period, the respiration rate of the constant high cores did not change significantly (linear regression: $\mathrm{P}=0.359$ ) indicating that the gradual reduction in 
On day 171, the high-low-high cores were returned to $10^{\circ} \mathrm{C}$ and respiration

2 rates increased by approximately $72 \%$. However, this rate was significantly less than

3 that measured on day 109, immediately before the temperature reduction (paired

4 t-test: $\mathrm{P}=0.037$; Fig. 1c). This indicated that the reduction in respiration rates

5 observed at $2^{\circ} \mathrm{C}$ was still apparent when samples were returned to $10^{\circ} \mathrm{C}$. Over the

6 following 28 days (i.e. days 172-200) the respiration rate increased by approximately

$722 \%$ with the rate measured on day 193 differing significantly from the rate measured

8 on day $172(\mathrm{P}=0.028$; Fig. $1 \mathrm{c})$. Further, the increase in respiration rates during this

9 period only occurred in the high-low-high samples and not in the constant high

10 samples $\left(\mathrm{P}=0.026\right.$; Fig. 1c). Thus, extended exposure to $10^{\circ} \mathrm{C}$ was required for the

11 respiration rates to recover to their pre-cooling levels.

\section{Temperature sensitivity of respiration}

15 At the end of the 200-day incubation period, the response of the constant high and 16 high-low samples to short-term changes in temperature was investigated. Overall, respiration rates were highly temperature sensitive, but there was no significant difference between treatments (Fig. 2; $\mathrm{P}=0.149$ ) suggesting that extended exposure to $2^{\circ} \mathrm{C}$ had not resulted in microbial respiration becoming more (or less) temperature sensitive.

However, the response of respiration to the increasing phase of the temperature manipulation was significantly higher in the high-low soils than in the constant high soils (high-low: $\mathrm{Q}_{10}=4.736 \pm 0.248$; constant high: $\mathrm{Q}_{10}=3.959 \pm 0.189$;

$24 \mathrm{P}=0.032$ ). This appeared to have been caused by a significant increase in the baseline 25 rate of respiration in the high-low soils as demonstrated by significantly (or 
1 marginally significantly) higher rates of respiration on the declining phase of the

2 temperature manipulation (Fig. $2 ; 6^{\circ} \mathrm{C}: \mathrm{P}=0.053,2^{\circ} \mathrm{C}: \mathrm{P}=0.001$ ). No corresponding

3 significant increase in the rate of respiration was observed in the constant-high

4 treatment. The $\mathrm{Q}_{10}$ values calculated for the declining phase of the manipulation were

5 similar and not significantly different (high-low: $\mathrm{Q}_{10}=3.859 \pm 0.214$; constant high:

$\left.6 \quad \mathrm{Q}_{10}=3.655 \pm 0.197 ; \mathrm{P}=0.497\right)$.

7

8 Substrate-induced respiration

10 A significantly greater rate of SIR (measured at $10^{\circ} \mathrm{C}$ in all cases) was observed in the

11 soil samples that were at $10^{\circ} \mathrm{C}$ at the end of the experiment compared to those that 12 were at $2^{\circ} \mathrm{C}\left(t\right.$-test: $\mathrm{P}=0.027 ; 75.3$ vs. $66.7 \mu \mathrm{g} \mathrm{g}^{-1}$ soil $\left.\mathrm{C} \mathrm{h}^{-1}\right)$.

\section{DISCUSSION}

\section{Thermal acclimation}

Our soil-cooling experiment produced no evidence that microbial respiration

19 acclimates to temperature. The length of incubation carried out in our experiment

20 should have allowed for thermal acclimation of microbial respiration to occur given

21 that changes in microbial communities have been observed between seasons in tundra

22 soils (Schadt et al. 2003; Lipson \& Schmidt 2004; Wallenstein et al. 2007), and in

23 response to temperature changes in laboratory experiments of a similar duration

24 (Pettersson \& Bååth 2003). Therefore, our results provide support for the modeling 25 studies (Kirschbaum 2004; Eliasson et al. 2005; Knorr et al. 2005) that have proposed 
1 that the decline in the initial positive response of soil respiration to increased

2 temperatures in long-term warming studies is due to substrate depletion and not 3 acclimation of microbial respiration. Unlike plants it appears that the respiration of free-living, heterotrophic soil 5 microbes does not acclimate to temperature. This is perhaps not surprising given the 6 fundamental differences that exist between autotrophic and heterotrophic organisms. 7 Whilst physiological acclimation serves to maintain a positive $\mathrm{C}$ balance in plants 8 when shifted to a higher growth temperature (Atkin \& Tjoelker 2003), it is unclear 9 what advantage microbes would gain from reduced activity once temperature 10 constraints have been relaxed. Thermal acclimation has been observed in mycorrhizal 11 fungi (Heinemeyer et al. 2006; Malcolm et al. 2008) and the fungal component of 12 lichens (Lange \& Green 2005), but the activity of these microbes is tightly linked to, 13 and controlled by (Heinemeyer et al. 2006), the rate of photosynthesis in their 14 symbiotic partners. As such, these organisms are not representative of free-living 15 heterotrophic microbes in soils.

16 Previously, it has been shown that the temperature sensitivity of microbial 17 activity may increase in microbial communities adapted to low temperatures (Monson 18 et al. 2006), and that it may be the temperature response rather than the baseline rate 19 of respiration that changes when systems acclimate to temperature (Luo et al. 2001; 20 Wan et al. 2007). However, we found little evidence for the microbial respiration 21 being more temperature sensitive in the cooled soils. The apparent down-regulation of 22 the temperature response, that was observed in previous studies (Luo et al. 2001; Wan 23 et al. 2007), was based on changes in seasonal $\mathrm{Q}_{10} \mathrm{~s}$ in intact plant-soil systems. These 24 results could have been caused by seasonal changes in the contributions of roots 25 versus soil microbes to total belowground respiration. Hartley et al. (2007a) 
1 demonstrated that rhizosphere respiration responded less to soil warming than

2 microbial respiration in bare soil. As the contribution of the more temperature

3 insensitive flux, rhizosphere respiration, is likely to be greatest during mid season, a

4 time when soil temperatures are likely to be highest, this could explain the apparent

5 reduction in the temperature sensitivity of respiration in warmed plots (i.e. differences

6 between warmed and ambient plots are expected to be lowest during the time of year

7 when rhizosphere respiration contributes the most to belowground respiration). Our

8 results indicate that it is unlikely that the development of a microbial community

9 which responds little to changes in temperature can explain the lower seasonal $\mathrm{Q}_{10} \mathrm{~S}$

10 measured in the warmed plots in previous studies (Luo et al. 2001; Wan et al. 2007).

11 In our study, by carrying out our measurements in the absence of a rhizosphere, we 12 avoided the possibility of microbial responses being mediated through changes in 13 plant activity.

\section{Adaptation enhancing a positive feedback}

17 Our study goes further than demonstrating that thermal acclimation does not occur in 18 these sub-arctic soils. Exposure to low temperatures for an extended period reduced 19 the rate of respiration beyond the initial short-term response (Fig. 1b) and, similarly, 20 extended exposure to moderate temperatures resulted in an increase in activity beyond 21 the instantaneous response to temperature (Fig. 1c). Further, as the rate of SIR 22 (measured at $10^{\circ} \mathrm{C}$ in all cases) was significantly lower in the cooled soils, it appears 23 the microbial community had been affected. Whether the lower SIR rate in the cooled 24 soil was due to a reduction in microbial biomass per se or reflected a shift in 25 microbial community structure is debatable. However, the results from our study 
1 suggest that the microbial community was altered by the cooling and that this resulted

2 in a further reduction in respiration rates. Therefore, at the low to moderate

3 temperatures experienced in many soils, such as the arctic soil investigated here, when

4 global warming increases soil temperatures it seems probable that $\mathrm{C}$ losses will be

5 enhanced by changes in microbial community functioning.

6 In support of this suggestion, a soil-warming study demonstrated that, during

7 winter months, microbial activity in warmed plots was higher than in control plots

8 even when measurements were made at a common temperature; it was concluded that

9 warming had produced a more active microbial community (Hartley et al. 2007a).

10 Further, it has been demonstrated that the temperature optimum for the activity of key

11 microbial enzymes in organic soils may shift with time of year (Fenner et al. 2005),

12 and that thermal tolerances of bacterial community activity gradually change in

13 response to temperature manipulations (Pettersson \& Bååth 2003). Rather than a

14 compensatory response, it appears that, in the longer term, changes in the microbial

15 community may result in a further increase in activity as temperatures rise. Therefore,

16 soil-C losses from cold environments, and during winter periods, are likely to be

17 enhanced by climate change due to changes in soil microbial communities amplifying

18 the instantaneous response to temperature.

19 Here we return to the issue of terminology; the changes in the microbial 20 community which resulted in the decreasing rate of respiration for the 60-day period 21 after cooling, and the increase in the rate of respiration following warming of the 22 high-low-high soils, should be termed adaptation as it almost certainly contains a 23 genetic component. We reiterate that the term acclimation is probably never 24 appropriate when referring to a change occurring at the level of the whole community. 
1 If a compensatory response is observed then perhaps the term "compensatory

2 adaptation" would be more appropriate.

Previously, studies which have modeled mineralization kinetics based on the

4 results of incubation studies have suggested that substrate pool sizes may increase at

5 higher temperatures (MacDonald et al. 1995; Waldrop \& Firestone 2004; Rasmussen

6 et al. 2006). Molecules that decompose in reactions with large activation energies are

7 likely to decompose especially slowly at low temperatures (Davidson \& Janssens

8 2006; Hartley \& Ineson 2008), but may become more available at increased

9 temperatures, potentially explaining the increased pool sizes and shifts in substrate

10 utilization patterns observed in these studies (e.g. Waldrop \& Firestone 2004). Within

11 this context, in the study presented here, the gradual reduction in respiration rates

12 post-cooling may reflect a loss of the most labile pool of substrates which are most

13 available to microbes at low temperatures. This may in turn have induced the changes

14 in the microbial community that occurred (reflected by the reduction in SIR). On

15 return to the warmer temperature, thermal constraints on substrate availability may

16 have been relaxed and the microbes again adapted to their prevailing environment.

This is just one potential explanation for the reduction in respiration rates that

18 occurred post-cooling and the changes in the microbial community. However, it is

19 clear that thermal acclimation of microbial respiration did not occur, and adaptive

20 responses of soil microbes to increasing temperatures may accelerate decomposition

21 rates, at least at the low to moderate temperatures experienced in many soils. 
1 Timescale of the response of microbial respiration to warming

3 In light of the findings of this study we can perhaps consider three separate processes

4 which may determine the rate of soil $\mathrm{C}$ losses from arctic soils over different

5 timescales. Firstly, in agreement with the study of Mikan et al. (2002), we found a

6 strong instantaneous response of microbial respiration to changes in temperature

7 (Fig. 2). When changes in the baseline rate of respiration were accounted for it

8 appeared that the temperature sensitivity of respiration was not affected by the

9 thermal regime the microbes had experienced.

10 Secondly, cooling reduced the baseline rate of respiration as the microbial

11 community was altered by the new temperature, and this medium-term response to the 12 temperature manipulation was reversible. It should be mentioned that there was some 13 evidence of a faster response of the microbial community to the warming than the 14 cooling treatment. It took almost 60 days for the full cooling effect to occur whilst 15 rates had fully recovered within 30 days of warming in the high-low-high samples. In 16 addition, there was some evidence of an almost immediate, partial up-regulation of 17 the baseline rate of respiration in the high-low soils during the short-term temperature 18 manipulation. Therefore, at a timescale of about 1 month, respiration rates are likely 19 to increase in warmer arctic soils as changes in the microbial community result in an 20 increase in the baseline rate.

21 Thirdly, at the decadal time scale, there may be a change in both total SOM 22 stocks as warming stimulates C loss, and also a change in the composition of SOM as 23 substrate pools with shorter turnover times are preferentially lost ( gren \& Bosatta, 24 2002; Kirschbaum 2004; Eliasson et al. 2005; Knorr et al. 2005). These changes will 25 result in a subsequent decline in the rates of microbial respiration. 
Finally, in situ, if higher decomposition rates increase soil nutrient availability

2 (Schmidt et al. 2002; Pregitzer et al. 2008), increased plant productivity may partly or

3 fully offset these C losses, and so determine the extent to which rates of microbial

4 respiration decline. However, further research is required to estimate the importance

5 of this potential feedback.

6

9 Compensatory thermal acclimation of soil microbial respiration did not occur in our 10 experiment. Rather, the effect of temperature on microbial community functioning 11 increased respiration rates beyond the instantaneous effect of temperature. This change. 
3 This work was carried out within the Natural Environment Research Council (NERC)

4 funded Arctic Biosphere Atmosphere Coupling at Multiple Scales (ABACUS) project

5 (a contribution to International Polar Year 2007-2008). We thank Lorna English and

6 Laura-Lee Shillam for their help with the microbial biomass analyses. This

7 manuscript was improved in response to the helpful comments of three referees.

8

9 REFERENCES

11 ACIA (2005). Arctic Climate Impact Assessment. Cambridge University Press, 12 Cambridge.

14 Ågren, G.I. \& Bosatta, E. (2002) Reconciling differences in predictions of 15 temperature response of soil organic matter. Soil Biol. Biochem., 34, 129-132.

16

17 Anderson, J.P.E. \& Domsch, K.H. (1978). Physiological Method for Quantitative

18 Measurement of Microbial Biomass in Soils. Soil Biol. Biochem., 10, 215-221.

19

20 Andrews, J.A., Matamala, R., Westover, K.M. \& Schlesinger, W.H. (2000).

21 Temperature effects on the diversity of soil heterotrophs and the $\delta^{13} \mathrm{C}$ of soil-respired $22 \mathrm{CO}_{2}$. Soil Biol. Biochem., 32, 699-706. 
1 Armstrong, A.F., Logan, D.C., Tobin, A.K., O'Toole, P. \& Atkin, O.K. (2006).

2 Heterogeneity of plant mitochondrial responses underpinning respiratory acclimation

3 to the cold in Arabidopsis thaliana leaves. Plant Cell Environ., 29, 940-949.

5 Atkin, O.K., Bruhn, D., Hurry, V.M., Tjoelker, M.G. (2005). The hot and the cold:

6 unravelling the variable response of plant respiration to temperature. Funct. Plant $7 \quad$ Biol., 32, 87-105.

9 Atkin, O.K. \& Tjoelker, M.G. (2003). Thermal acclimation and the dynamic response 10 of plant respiration to temperature. Trends Plant Sci., 8, 343-351.

12 Balser, T.C., McMahon, K.D., Bart, D., Bronson, D., Coyle, D.R., Craig, N., Flores13 Mangual, M.L., Forshay, K., Jones, S.E., Kent, A.E. \& Shade, A.L. (2006). Bridging 14 the gap between micro - and macro-scale perspectives on the role of microbial 15 communities in global change ecology. Plant Soil, 289, 59-70.

17 Cox, P.M., Betts, R.A., Jones, C.D., Spall, S.A. \& Totterdell, I.J. (2000). Acceleration 18 of global warming due to carbon-cycle feedbacks in a coupled climate model. Nature, $19 \quad 408,184-187$.

21 D'Amico, S., Collins, T., Marx, J.C., Feller, G. \& Gerday, C. (2006). Psychrophilic 22 microorganisms: challenges for life. EMBO rep., 7, 385-389.

24 Davidson, E.A. \& Janssens, I.A. (2006). Temperature sensitivity of soil carbon 25 decomposition and feedbacks to climate change. Nature, 440, 165-173. 
2 Eliasson, P.E., McMurtrie, R.E., Pepper, D.A., Stromgren, M., Linder, S. \& Ågren, 3 G.I. (2005). The response of heterotrophic $\mathrm{CO}_{2}$ flux to soil warming. Glob. Change 4 Biol., 11, 167-181.

6 Enquist, B. J. (2007). Journal Club - An Ecologist wonders how biotic feedback 7 matters to global-change research. Nature, 450, 139.

9 Fang, C.M., Smith, P., Moncrieff, J.B. \& Smith, J.U. (2005). Similar response of 10 labile and resistant soil organic matter pools to changes in temperature. Nature, 433, $11 \quad 57-59$.

13 Fenner, N., Freeman, C. \& Reynolds, B. (2005). Observations of a seasonally shifting 14 thermal optimum in peatland carbon-cycling processes; implications for the global 15 carbon cycle and soil enzyme methodologies. Soil Biol. Biochem., 37, 1814-1821.

17 Hartley, I.P., Heinemeyer, A., Evans, S.P. \& Ineson, P. (2007a). The effect of soil 18 warming on bulk soil vs. rhizosphere respiration. Glob. Change Biol., 13, 2654-2667.

20 Hartley, I.P., Heinemeyer, A., \& Ineson, P. (2007b). Effects of three years of soil 21 warming and shading on the rate of soil respiration: substrate availability and not 22 thermal acclimation mediates observed response. Glob. Change Biol., 13, 1761-1770. 
1 Hartley, I.P. \& Ineson, P. (2008) Substrate quality and the temperature sensitivity of 2 soil organic matter decomposition. Soil Biol. Biochem., doi: 3 10.1016/j.soilbio.2008.01.007.

5 Heinemeyer, A., Ineson, P., Ostle, N. \& Fitter, A.H. (2006). Respiration of the 6 external mycelium in the arbuscular mycorrhizal symbiosis shows strong dependence 7 on recent photosynthates and acclimation to temperature. New Phytol., 171, 159-170.

9 Hobbie, S.E., Schimel, J.P., Trumbore, S.E. \& Randerson, J.R. (2000). Controls over 10 carbon storage and turnover in high-latitude soils. Glob. Change Biol., 6, 196-210.

12 IPCC (2007) Climate Change 2007: The Physical Science Basis. Cambridge 13 University Press, Cambridge, 2007.

15 Kirschbaum, M.U.F. (1995). The temperature-dependence of soil organic-matter 16 decomposition, and the effect of global warming on soil organic-C storage. Soil Biol. 17 Biochem., 27, 753-760.

19 Kirschbaum, M.U.F. (2004). Soil respiration under prolonged soil warming: are rate 20 reductions caused by acclimation or substrate loss? Glob. Change Biol., 10, 1870211877.

23 Knorr, W., Prentice, I.C., House, J.I. \& Holland, E.A. (2005). Long-term sensitivity of 24 soil carbon turnover to warming. Nature, 433, 298-301. 
1 Lange, O.L. \& Green, T.G.A. (2005). Lichens show that fungi can acclimate their

2 respiration to seasonal changes in temperature. Oecologia, 142, 11-19.

3

4 Lipson, D.A. \& Schmidt, S.K. (2004). Seasonal changes in an alpine soil bacterial 5 community in the Colorado Rocky Mountains. Appl. Environ. Microbiol., 70, 286762879.

7

8 Luo, Y. (2007) Terrestrial Carbon-Cycle Feedback to Climate Warming. Annu. Rev.

9 Ecol. Evol. Syst., 38, 683-712.

11 Luo, Y., Wan, S.Q., Hui, D.F. \& Wallace, L.L. (2001). Acclimatization of soil 12 respiration to warming in a tall grass prairie. Nature, 413, 622-625.

14 MacDonald, N.W., Zak, D.R. \& Pregitzer, K.S. (1995). Temperature effects on 15 kinetics of microbial respiration and net nitrogen and sulfur mineralization. Soil Sci. 16 Soc. Am. J., 59, 233-240.

18 Malcolm, G.M., López-Gutiérrez, J.C., Koide, R.T. \& Eissenstat, D.M. (2008) 19 Acclimation to temperature and temperature sensitivity of metabolism by 20 ectomycorrhizal fungi. Glob. Change Biol., doi: 10.1111/j.1365-2486.2008.01555.x.

22 Mikan, C.J., Schimel, J.P. \& Doyle, A.P. (2002). Temperature controls of microbial 23 respiration in arctic tundra soils above and below freezing. Soil Biol. Biochem., 34, $24 \quad 1785-1795$. 
1 Monson, R.K., Lipson, D.L., Burns, S.P., Turnipseed, A.A., Delany, A.C., Williams,

2 M.W. \& Schmidt, S.K. (2006). Winter forest soil respiration controlled by climate and

3 microbial community composition. Nature, 439, 711-714.

4

5 Oechel, W.C., Vourlitis, G.L., Hastings, S.J., Zulueta, R.C., Hinzman, L. \& Kane, D.

6 (2000). Acclimation of ecosystem $\mathrm{CO}_{2}$ exchange in the Alaskan Arctic in response to 7 decadal climate warming. Nature, 406, 978-981.

8

9 Pettersson, M. \& Bååth, E. (2003). Temperature-dependent changes in the soil 10 bacterial community in limed and unlimed soil. FEMS Microbiol. Ecol., 45, 13-21.

12 Pietikäinen, J., Pettersson, M. \& Bååth E. (2005). Comparison of temperature effects 13 on soil respiration and bacterial and fungal growth rates. FEMS Microbiol. Ecol., 52, $14 \quad 49-58$.

16 Post, W.M., Emanuel, W.R., Zinke, P.J. \& Stangenberger, A.G. (1982). Soil carbon 17 pools and world life zones. Nature, 298, 156-159.

19 Pregitzer, K.S., Burton, A.J., Zak, D.R. \& Talhelm, A.F. (2008). Simulated chronic 20 nitrogen deposition increases carbon storage in Northern Temperate forests. Glob. 21 Change Biol., 14, 142-153.

23 Raich, J.W. \& Schlesinger, W.H. (1992). The global carbon dioxide flux in soil 24 respiration and its relationship to vegetation and climate. Tellus B, 44, 81-99. 
1 Rasmussen, C., Southard, R.J. \& Horwath, W.R. (2006). Mineral control of organic

2 carbon mineralization in a range of temperate conifer forest soils. Glob. Change Biol., $3 \quad 12,834-847$.

4

5 Rustad, L.E., Campbell, J.L., Marion, G.M., Norby, R.J., Mitchell, M.J., Hartley, 6 A.E., Cornelissen, J.H.C. \& Gurevitch, J. (2001). A meta-analysis of the response of 7 soil respiration, net nitrogen mineralization, and aboveground plant growth to 8 experimental ecosystem warming. Oecologia, 126, 543-562.

10 Schadt, C.W., Martin, A.P., Lipson, D.A. \& Schmidt, S.K. (2003). Seasonal dynamics 11 of previously unknown fungal lineages in tundra soils. Science, 301, 1359-1361.

13 Schmidt, I.K., Jonasson, S., Shaver, G.R., Michelsen, A. \& Nordin, A. (2002). 14 Mineralization and distribution of nutrients in plants and microbes in four arctic 15 ecosystems: responses to warming. Plant Soil, 242, 93-106.

17 van Wijk, M.T., Williams, M. \& Shaver, G.R. (2005). Tight coupling between leaf 18 area index and foliage $\mathrm{N}$ content in arctic plant communities. Oecologia, 142, 42119427.

21 Waldrop, M.P. \& Firestone, M.K. (2004). Altered utilization patterns of young and 22 old soil $\mathrm{C}$ by microorganisms caused by temperature shifts and $\mathrm{N}$ additions. 23 Biogeochem., 67, 235-248. 
1 Wallenstein, M.D., McMahon, S. \& Schimel, J. (2007). Bacterial and fungal

2 community structure in Arctic tundra tussock and shrub soils. FEMS Microbiol. Ecol., $359,428-435$.

5 Wan, S., Norby, R.J., Ledford, J. \& Weltzin, J.F. (2007). Responses of soil respiration

6 to elevated $\mathrm{CO}_{2}$, air warming, and changing soil water availability in a model old-field 7 grassland. Glob. Change Biol., 13, 2411-2424.

9 Weintraub, M.N. \& Schimel, J.P. (2005). Nitrogen cycling and the spread of shrubs 10 control changes in the carbon balance of arctic tundra ecosystems. Bioscience, 55, $11408-415$.

13 Zogg, G.P., Zak, D.R., Ringelberg, D.B., MacDonald, N.W., Pregitzer, K.S. \& White, 14 D.C. (1997). Compositional and functional shifts in microbial communities due to soil 15 warming. Soil Sci. Soc. Am. J., 61, 475-481.

17 Zaragoza-Castells, J., Sánchez-Gómez, D., Hartley, I.P., Matesanz, S., Valladares, F., 18 Lloyd, J. \& Atkin, O.K. (2008). Climate-dependent variations in leaf respiration in a 19 dry-land, low productivity Mediterranean forest: the importance of acclimation in 20 both high-light and shaded habitats. Funct. Ecol., 22, 172-184.

22 Zhang, W., Parker, K.M., Luo, Y., Wan, S., Wallace, L.L. \& Hu, S. (2005). Soil 23 microbial responses to experimental warming and clipping in a tallgrass prairie. Glob. 24 Change Biol., 11, 266-277. 
3 Figure 1 The mean soil respiration rates in the three different temperature treatments

4 (constant high - $\mathbf{\Delta}-$, high-low $\cdots \nabla \cdot \cdots$, , high-low-high --O_-). Error bars represent

$5 \pm 1 \mathrm{SE}$ (constant high and high-low: $\mathrm{n}=10$; high-low-high: $\mathrm{n}=6$ ). The main panel (a)

6 shows the whole of the incubation period during which respiration measurements

7 were made. The timing of the reduction in temperature from $10^{\circ} \mathrm{C}$ to $2^{\circ} \mathrm{C}$ in the high-

8 low and high-low-high treatments is indicated as is the subsequent return to $10^{\circ} \mathrm{C}$ in

9 the high-low-high treatment. Panels (b) and (c) highlight the periods of key interest.

10 Panel (b) shows the decline in the rate of respiration at $2^{\circ} \mathrm{C}$ over the first 60 days at

11 the lower incubation temperature in the high-low and high-low-high treatments.

12 Linear regressions are fitted to each temperature treatment separately although there is

13 no significant difference between the two fitted lines (high-low (dotted line):

$14 \mathrm{y}=-0.0112 \mathrm{x}+4.00, \mathrm{R}^{2}=0.817 ;$ high-low-high (dashed line): $\mathrm{y}=-0.0135 \mathrm{x}+4.36$,

$\left.15 \mathrm{R}^{2}=0.815\right)$. Panel (c) shows the rate of respiration at $10^{\circ} \mathrm{C}$ in the high-low-high and

16 constant high samples immediately after the high-low-high samples were returned to

$1710^{\circ} \mathrm{C}$. The horizontal dashed line indicates the mean rate of respiration in the high-

18 low-high samples on day 109 immediately before the high-low-high samples were

19 transferred to $2^{\circ} \mathrm{C}$. Initially the rate of respiration in the high-low-high samples was

20 significantly less than on day 109 (paired t-test: $\mathrm{P}=0.037$ ) and significantly lower

21 than in the constant high treatment ( $\mathrm{t}$-test: $\mathrm{P}=0.044)$, but these differences were

22 subsequently lost as the respiration rates in the high-low-high samples increased. A

23 significant interaction term between time and temperature treatment (repeated

24 measures ANOVA; $\mathrm{P}=0.026$ ) indicated that the increase in respiration rates only

25 occurred in the high-low-high samples. 
1 Figure 2 The response of respiration to the short-term changes in temperature in the

2 high-low and constant high samples. Mean respiration rates on both the increasing and 3 decreasing phase of the temperature manipulation are shown. Error bars represent $4+1 \mathrm{SE}(\mathrm{n}=6)$. In the high-low samples, there was a significant increase in the rate of 5 respiration measured at $2{ }^{\circ} \mathrm{C}$ on the declining phase of the manipulation relative to the 6 rate measured on the increasing phase (labeled “*”)..The mean $\mathrm{Q}_{10}$ values 7 (proportional change in the rate of respiration given a $10^{\circ} \mathrm{C}$ change in temperature), 8 calculated from mean respiration rates at each temperature, were $4.25 \pm 0.224$ for the 9 high-low treatment and $3.80 \pm 0.186$ for the constant high treatment. There was no 10 significant difference between these two $\mathrm{Q}_{10}$ values $(t$-test: $\mathrm{P}=0.149)$. 
Figure 1

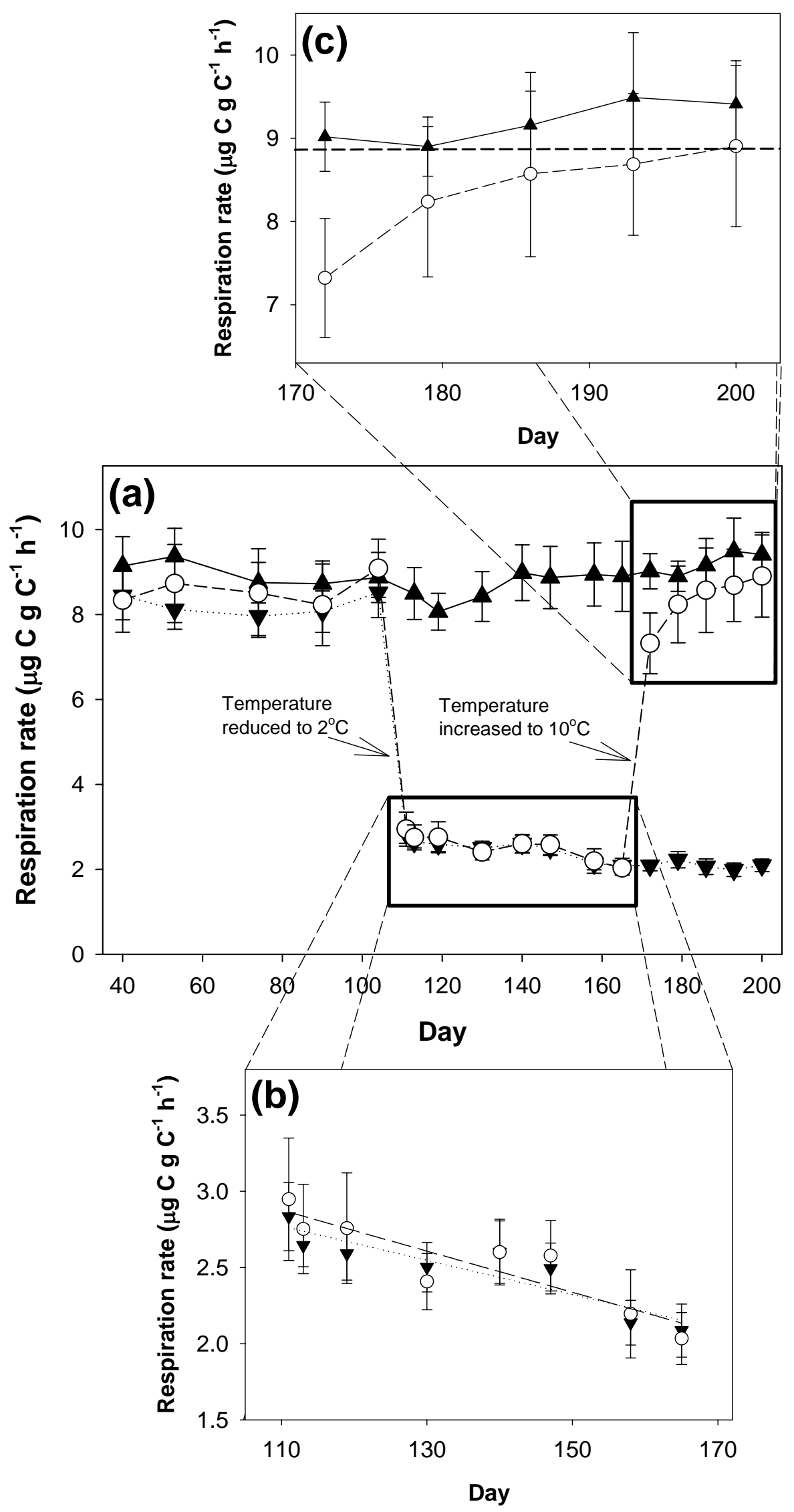


Figure 2

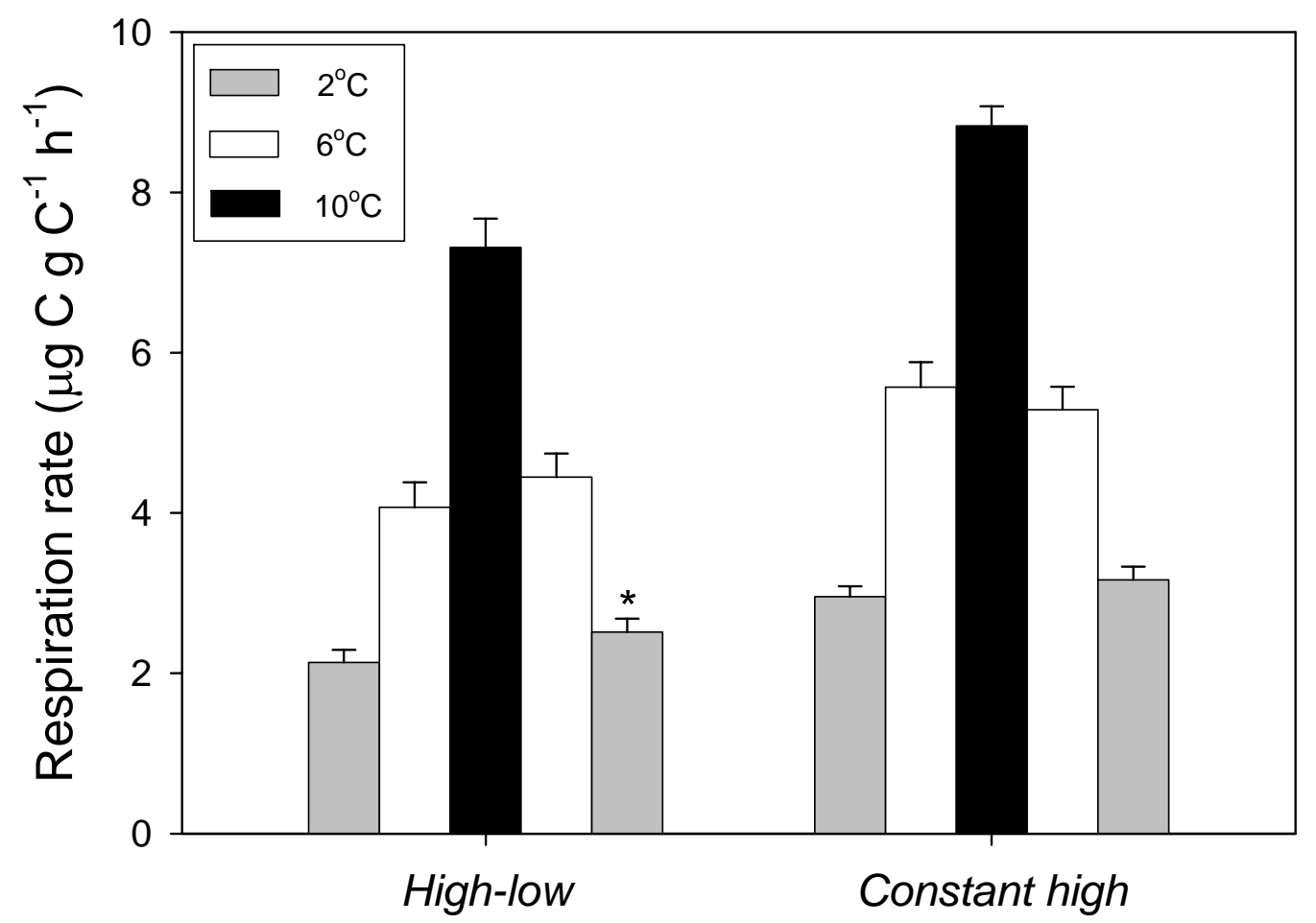

2
3
4
5
6
7
8
10 